\title{
Acute carpal tunnel syndrome as a result of spontaneous bleeding
}

\author{
Chenicheri Balakrishnan MD, Payam Jarrahnejad MD, Anila Balakrishnan BS, William C Huettner MD
}

\begin{abstract}
C Balakrishnan, P Jarrahnejad, A Balakrishnan, WC Huettner. Acute carpal tunnel syndrome as a result of spontaneous bleeding. Can J Plast Surg 2008;16(3):168-169.

Acute carpal tunnel syndrome is the most common compression neuropathy of the upper extremity following trauma. A rare occurence of spontaneous bleeding into the carpal tunnel, presenting as acute carpal tunnel syndrome, is presented.
\end{abstract}

\section{Syndrome du tunnel carpien aigu consécutif à une hémorragie spontanée}

Le syndrome du tunnel carpien est la neuropathie par compression la plus fréquente à survenir au niveau des membres supérieurs par suite de traumatismes. On présente ici un cas rare d'hémorragie spontanée au niveau du tunnel carpien ayant donné lieu à un syndrome aigu du tunnel carpien.

Key Words: Carpal tunnel syndrome; Spontaneous bleeding

Classic carpal tunnel syndrome (CTS) occurs most often in women, and manifests as hypoesthesia and tingling in the median nerve distribution distal to the wrist joint. In acute CTS (ACTS), the intracarpal interstitial pressure rises above the threshold, and capillary blood flow is reduced below the level of median nerve viability. This leads to ischemia of the muscles and nerves, resulting in the clinical signs and symptoms. ACTS due to spontaneous bleeding into the carpal tunnel is rare. We report a patient who developed ACTS from spontaneous bleeding into the carpal tunnel following strenuous exercise.

\section{CASE PRESENTATION}

A 51-year-old man presented to the emergency department with acute pain and swelling of the right hand following a workout at a gym. He had no history of serious illness in the past. Medications included acetylsalicylic acid $(81 \mathrm{mg} /$ day $)$ and vitamin $\mathrm{E}$ once per day. His pain started after his workout and increased over a $2 \mathrm{~h}$ period. There was no history of trauma. His hematological work-up was negative. He complained of tingling and paresthesia of the median nerve distribution.

On examination, there was swelling of the hand with slight bluish discolouration (Figure 1). The wrist was maintained in a flexed position. The signs and symptoms were those of acute tenosynovitis originating in the common flexor synovial sheath at the wrist with associated paresthesia in the distribution area of the median nerve in the hand.

$\mathrm{X}$-rays of the wrist and hand were negative. A clinical diagnosis of ACTS was made. He underwent decompression of the carpal tunnel under general anesthesia. At exploration, blood was seen inside the carpal tunnel (Figure 2). The carpal tunnel was decompressed. His symptoms improved following decompression and at six weeks he had full function of the hand.

\section{DISCUSSION}

Phalen (1) made significant contributions to our understanding of the etiology, diagnosis and management of chronic

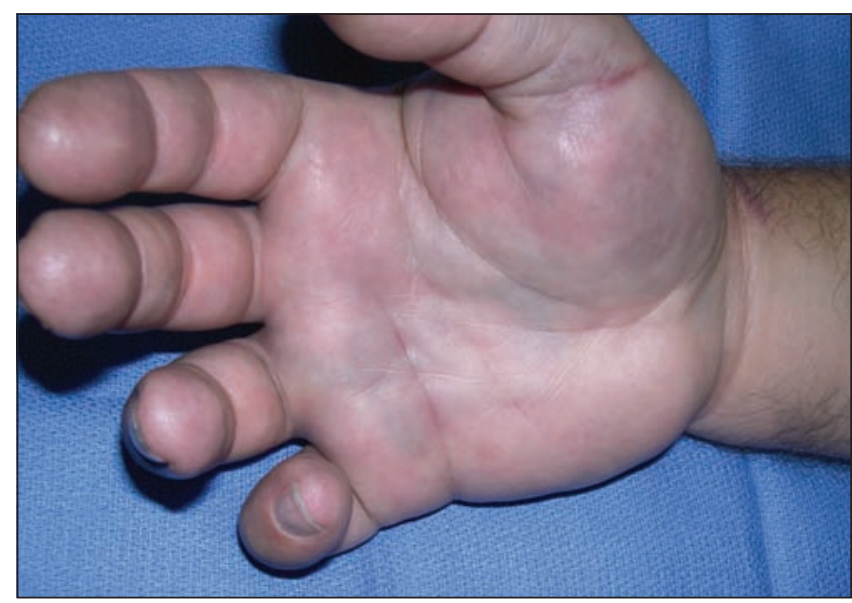

Figure 1) Swelling of the hand

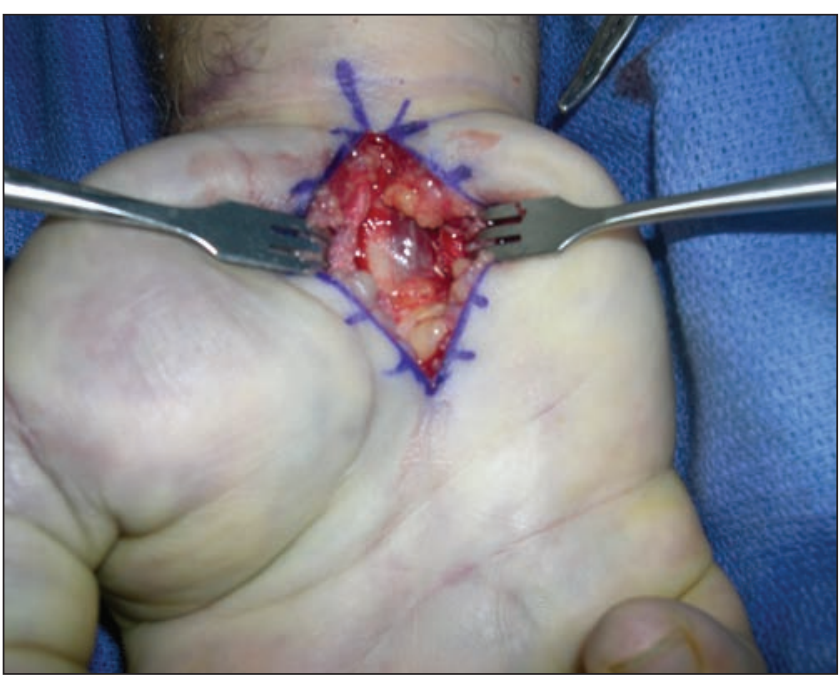

Figure 2) At exploration, blood seen within the carpal tunnel 
CTS, noting that any condition increasing the volume of contents of the carpal tunnel could compress the median nerve.

Phalen distinguished those patients with median nerve neuropathy of traumatic origin from those in his description of classic CTS, calling the former "tardy median nerve palsy" after the more common tardy ulnar nerve palsy. In the classic CTS, thickening of the flexor synovium is the most common etiology of compression and chronic ischemia of the median nerve. This is a result of an underlying rheumatological process in the majority of cases, consistent with the noted improvement seen in many patients after corticosteroid injection into the wrist.

ACTS has been reported from various causes. Etiologies include bleeding secondary to chronic lymphatic leukemia, hemophilia, Colles' fracture of the wrist, epiphyseal fracture (Salter II) of the distal radius, bleeding secondary to giant cell tumour of the tendon sheath, unstable distal radioulnar joint, displaced intra-articular fracture of the distal radius, rheumatoid synovitis and vasculitis, Hansen's disease and trans-scaphoid perilunar fracture dislocation of the wrist. Other causes include gout, pseudogout, foreign body within the carpal tunnel and acute thrombosis of persistent median artery (2-18).

Increased carpal tunnel pressure has been reported in the acute phase after Colles' fracture. The trauma itself causes increased carpal tunnel pressure due to edema and bleeding. Volar flexion of the wrist decreases the space in the carpal tunnel, which also increases the pressure. Early recognition of median nerve compression in the carpal tunnel is vital. The signs of median nerve compression should be looked for in all cases of wrist trauma (2).

ACTS secondary to intraneural hemorrhage of the median nerve is unusual. Most reports involve hemophilia. Only rarely

\section{REFERENCES}

1. Phalen GS. The carpal-tunnel syndrome. Seventeen years' experience in diagnosis and treatment of six hundred fifty-four hands. J Bone Joint Surg Am 1966;48:211-28.

2. McClain EJ, Wissinger HA. The acute carpal tunnel syndrome: Nine case reports. J Trauma 1976;16:75-8.

3. Kiongsholm J, Olerud C. Carpal tunnel pressure in the acute phase after Colles' fracture. Arch Orthop Trauma Surg 1986;105:183-6.

4. Ehrmann L, Lechner K, Mamoli B, Novotny C, Kos K. Peripheral nerve lesions in haemophilia. J Neurol 1981;225:175-82.

5. Howie CR, Buxton R. Acute carpal tunnel syndrome due to spontaneous haemorrhage. J Hand Surg [Br] 1984;9:137-8.

6. Kilpatrick T, Leyden M, Sullivan J, Lawler G, Grossman H. Acute median nerve compression by haemorrhage from acute myelomonocytic leukaemia. Med J Aust 1985;142:51-2.

7. Faithfull DK, Wallace RF. Traumatic rupture of median artery an unusual cause for acute median nerve compression. J Hand Surg [Br] 1987;12:233-5.

8. Bindiger A, Zelenik J, Kuschner S, Gellman H. Spontaneous acute carpal tunnel syndrome in an anticoagulated patient. Bull Hosp Jt Dis 1995;54:52-3.

9. Nkele C. Acute carpal tunnel syndrome resulting from haemorrhage into the carpal tunnel in a patient on warfarin. J Hand Surg [Br] 1986;11:455-6.

10. Parthenis DJ, Karagkevrekis CB, Waldram MA. von Willebrand's has this disorder occurred in a patient receiving anticoagulation therapy, and in these cases, there is usually a history of trauma. ACTS due to spontaneous bleeding without a history of injury is rare. In these patients, hematological investigations are required to rule out von Willebrand's disease (10).

Peripheral nerve lesions in hemophilia have been reported, with the average age of the patients at the time of development of lesion at 26.4 years (4). Correlations between severity of hemophilia and frequency of occurrence of lesions were found; patients with mild hemophilia did not show peripheral nerve disturbances. The nerves involved include the following: maxillary, radial, median, ulnar, obturator, lateral cutaneous nerve of thigh, femoral, peroneal and tibial. In this study, motor nerve conduction velocity, distal latency and compound nerve action potentials were systematically examined on both sides of the body. This did not show any signs of subclinical peripheral nerve lesions (4).

When confronted with median nerve neuropathy in the setting of blunt wrist trauma, the decision must be made as to whether the neuropathy is due to nerve contusion or ACTS, indicating observation or carpal tunnel release, respectively (19). A careful history will reveal whether the hypoesthesia occured immediately following the trauma, as in contusion, or delayed, as in ACTS. Two-point discrimination should be assessed to note progression and to also assess recovery if an operation is undertaken.

ACTS from wrist trauma or other origin differs most notably from classic CTS in the speed with which it must be dealt; immediate carpal tunnel release gives the most timely and full recovery. In the present patient, early decompression resulted in complete recovery.

disease presenting as acute carpal tunnel syndrome. J Hand Surg [Br] 1998;23:114

11. Lynch AC, Lipscomb PR. The carpal tunnel syndrome and Colles' fractures. JAMA 1963;185:363-6.

12. Gaur SC, Kulshreshtha K, Swarup S. Acute carpal tunnel syndrome in Hansen's disease. J Hand Surg [Br] 1994;19:286-7.

13. Ogilvie C, Kay RM. Fulminating carpal tunnel syndrome due to gout. J Hand Surg [Br] 1988;13:42-3.

14. Chiu KY, Ng WF, Wong WB, Choi CH, Chow SP. Acute carpal tunnel syndrome caused by pseudogout. J Hand Surg [Am] 1992;17:299-302.

15. Bonatz E, Seabol KE. Acute carpal tunnel syndrome in a patient taking Coumadin: Case report. J Trauma 1993;35:143-4.

16. Balakrishnan C, Bradt LM, Sylora RL, Graff N. Acute carpal tunnel syndrome from foreign body in the carpal tunnel. Can J Plast Surg 2002;10:42-3.

17. Balakrishnan C, Smith FM, Puri P. Acute carpal tunnel syndrome from a thrombosed persistent median artery. J Emerg Med 1999;17:437-9.

18. Sterling AP, Eshraghi A, Anderson WJ, Habermann ET. Acute carpal tunnel syndrome secondary to a foreign body within the median nerve. Bull Hosp Joint Dis 1972;33:130-4.

19. Mack GR, McPherson SA, Lutz RB. Acute median neuropathy after wrist trauma. The role of emergent carpal tunnel release. Clin Orthop Relat Res 1994;300:141-6. 